\title{
BMJ Open Prevalence, nature and risk factors for medication administration omissions in English NHS hospital inpatients: a retrospective multicentre study using Medication Safety Thermometer data
}

\author{
Paryaneh Rostami, ${ }^{\oplus 1}$ Calvin Heal, ${ }^{2,3}$ Abigail Harrison, ${ }^{4}$ Gareth Parry, ${ }^{5,6}$ \\ Darren M Ashcroft, ${ }^{1,7}$ Mary P Tully ${ }^{1}$
}

To cite: Rostami P, Heal C, Harrison A, et al. Prevalence, nature and risk factors for medication administration omissions in English NHS hospital inpatients: a retrospective multicentre study using Medication Safety Thermometer data. BMJ Open 2019;9:e028170. doi:10.1136/ bmjopen-2018-028170

- Prepublication history and additional material for this paper are available online. To view these files, please visit the journal online (http://dx.doi org/10.1136/bmjopen-2018028170).

Received 25 November 2018 Revised 14 March 2019 Accepted 2 May 2019
Check for updates

(C) Author(s) (or their employer(s)) 2019. Re-use permitted under CC BY-NC. No commercial re-use. See rights and permissions. Published by BMJ.

For numbered affiliations see end of article.

Correspondence to Dr Paryaneh Rostami; P.Rostami@nhs.net

\section{ABSTRACT}

Objective To determine the prevalence, nature and predictors of patients having medication administration omissions in hospitals.

Methods All medication administration omissions data collected using the standardised methodology of the Medication Safety Thermometer in January 2015 were examined. Hospital inpatients prescribed at least one medication were included in the analysis. Multilevel logistic regression models ascertained the effects of patients' gender, age, number of prescribed medicines, ward specialty and medicines reconciliation initiation status on the likelihood of having omissions. Valid clinical reasons (VCRs) were excluded from regression models. A sensitivity analysis, excluding patient refusal (PR) omissions, was also conducted.

Results The final study sample included 5708 patients from 320 wards in 37 hospitals. Excluding VCRs, $30 \%$ of patients had medication administration omissions ( $95 \% \mathrm{Cl} 29$ to 30). Approximately half of patients with omissions had refused medicines $(51 \%, 95 \% \mathrm{Cl} 49$ to 53$)$. Univariable analysis suggested that all variables were significantly associated with omissions. However, in the multivariable model, significant differences were only observed regarding the numbers of medicines patients were prescribed and their ward specialty. Patients prescribed more than 20 medications were approximately five times more likely to have had omissions than patients prescribed one to four medications ( $0 \mathrm{R} 4.99$, $95 \% \mathrm{Cl} 3.22$ to 7.73 ). Patients on surgical wards were also more likely to have had omissions than those on medical wards (OR $1.58,95 \% \mathrm{Cl} 1.14$ to $2.18, \mathrm{p}=0.006)$, but there was no significant difference when PRs were excluded (OR 0.5 , $95 \% \mathrm{Cl} 0.27$ to $1.22, \mathrm{p}=0.473$ ).

Conclusion Medication administration omissions are a substantial problem that affect many hospital patients, and certain patient groups are at higher risk. Specific interventions are required targeting the underlying reasons for medication omissions for different patient subgroups.

\section{BACKGROUND}

Several studies and reports have highlighted that $10 \%$ of patients are harmed by healthcare ${ }^{1-3}$; in particular, adverse events

\section{Strengths and limitations of this study}

- This study adds to knowledge about patients with medication administration omissions and potential predictors using a large routinely collected data set.

- This multi-institutional study used Medication Safety Thermometer data from a variety of wards with different specialties in hospitals located across England to learn about medication safety.

- Although the data were collected using a standardised form, multiple healthcare staff were involved in data collection, leading to potential variations in data collection practice, and data collected relied on complete medical records and drug charts.

- However, the median number of patients that data were collected on per ward were calculated to be 19 (IQR 12-24) and 129 (IQR 47-207) patients per hospital; as these ranges were not wide, the finding suggests that the data are being collected somewhat consistently across hospitals and wards.

- Although multilevel regression modelling occurred to account for variance between the wards and hospitals, findings may not be generalisable to other hospitals not in this study.

associated with medication appear to be a primary cause of this harm. ${ }^{245}$ These adverse drug events caused by medication errors are associated with additional healthcare costs and increased lengths of stay for hospital inpatients. ${ }^{6}$

One of the most common types of medication error appears to be medication administration errors. $^{7-9}$ A medication administration error is the administration of a dose, or the lack of administration (omission) of a dose, of medication that deviates from the prescription, as written on the patient chart, or from hospital policy and procedures. ${ }^{1011} \mathrm{~A}$ systematic review of medication administration error prevalence 
found that they were common and affected approximately $19.1 \%$ of doses due to be administered in hospitals. ${ }^{4}$ Furthermore, the review found that medication administration omissions were the biggest cause of medication administration errors. ${ }^{4}$ This study focuses on medication administration omissions, which will hereafter be referred to as omissions.

Within healthcare settings, omissions are a well-known issue among healthcare staff who have often reported anecdotal evidence of prescribed medicines not reaching patients. ${ }^{12}{ }^{13}$ A number of studies have quantified the issue of omissions within hospitals, ${ }^{12}$ but these either have often been small studies, ${ }^{14-17}$ focused on one type of medication group,$^{18}$ or have been conducted in one organisation $^{51519-21}$ or specific specialty area only. ${ }^{5162122}$ The rates of omissions reported by these previous studies have been highly variable, partly due to the varying definitions and classification systems used in studies. ${ }^{15}$ Furthermore, most of the aforementioned studies have investigated the rate of omissions as the number of doses that have not been administered, ${ }^{18} 192223$ rather than the number of patients that have not received their medicines. While it is useful to know about the former, it is also useful to know about the latter so that specific patient groups can be prioritised for improvement of omissions.

Focussing on patients with omissions, rather than omitted doses, is in line with the NHS 'Harm Free Care' programme. This programme was initiated by a large group of NHS healthcare professionals and aims to encourage those involved with healthcare improvement to 'stop dealing with safety issues in silos, (and) think about complications from the patient's perspective and aim for the absence of all harm to each and every patient'. ${ }^{24}$ In terms of medication safety, this means that healthcare organisations should aim to measure and improve the proportion of patients who are free from harm from medication-related adverse events, including omissions.

One tool that is part of the Harm Free Care programme, focussing on improving medication safety for patients, is the NHS Medication Safety Thermometer (MedsST). The MedsST has been used to collect medication safety data by over 100 English hospitals since $2013 .^{24}$ It was developed to help healthcare organisations monitor harm due to medication errors and was designed to measure improvement over time. ${ }^{24}$ It consists of three steps, which focus on potential and actual harm. ${ }^{25}$ The potential harm is measured using process measures, such as the frequency of omissions, specifically whether any of the patient's prescribed medications have not been given in the 24 hours prior to the point of survey. Actual harm is also measured by reviewing whether harm has occurred from four classes of drugs that can cause patient harm if not administered appropriately: anticoagulants, injectable sedatives, insulin and opiates. These four medication classes were identified as the most likely to cause death and severe harm by the UK National Reporting and Learning System, 2005-2010. ${ }^{24} 26$
It is recommended that the MedsST tool is used on 1 day per month to survey all patients on wards using the MedsST. ${ }^{25}$ The data collected from the MedsST tool can be reviewed and used by organisations to get a 'snapshot' of the level of medication safety harm that is occurring, and measure associated improvement at local levels, but the data can also be aggregated for use nationally. ${ }^{24}$ Previous studies have identified that healthcare staff trust the MedsST data collected in hospitals ${ }^{27}$ and that some data have been used for improvement of medication safety, in particular improvement of omissions. ${ }^{13}$

After collecting and inputting MedsST data online, organisations can review and use their collected data immediately. While the data have been used within certain wards and organisations to aid improvement, ${ }^{1327}$ nationally aggregated MedsST data have not yet been used to learn about the magnitude of medication safety issues, such as omissions.

\section{AIMS}

The aims of this study were to use MedsST data collected by hospitals to identify the prevalence of patients who have had medication administration omissions in secondary care, to describe the nature of medication administration omissions and to investigate predictors of patients having omissions.

\section{METHODS}

\section{Data source}

This study involved a secondary analysis of data that had already been collected and compiled. The data had been collected by healthcare staff in various hospitals using the MedsST and compiled by Haelo (an independent innovation and evaluation organisation hosted by Salford Royal Foundation Trust). Data collected from community settings were excluded, as our previous study identified that NHS staff do not trust MedsST data collected in community settings. The REporting of studies Conducted using Observational Routinely-collected Data (RECORD) statement ${ }^{28}$ was used to guide the reporting of this article (online supplementary appendix 1). The RECORD statement is an extension of the more commonly used Strengthening the Reporting of Observational Studies in Epidemiology checklist, ${ }^{29}$ developed specifically for routinely collected healthcare data.

There is open -access to data provided in statistical process control charts in a dedicated dashboard, which can be accessed online (www.SafetyThermometer. nhs.uk). ${ }^{25}$ For the purpose of this study, raw data were obtained from Haelo, which managed the data collection between 2013 and2017.

The data collected included demographic information on gender (male/female), age band $(<18,19-24,25-44$, 45-69 and >70years), clinical specialty of the ward a patient was on (eg, medical, surgical or other), medication safety process measures (allergy status completion, 


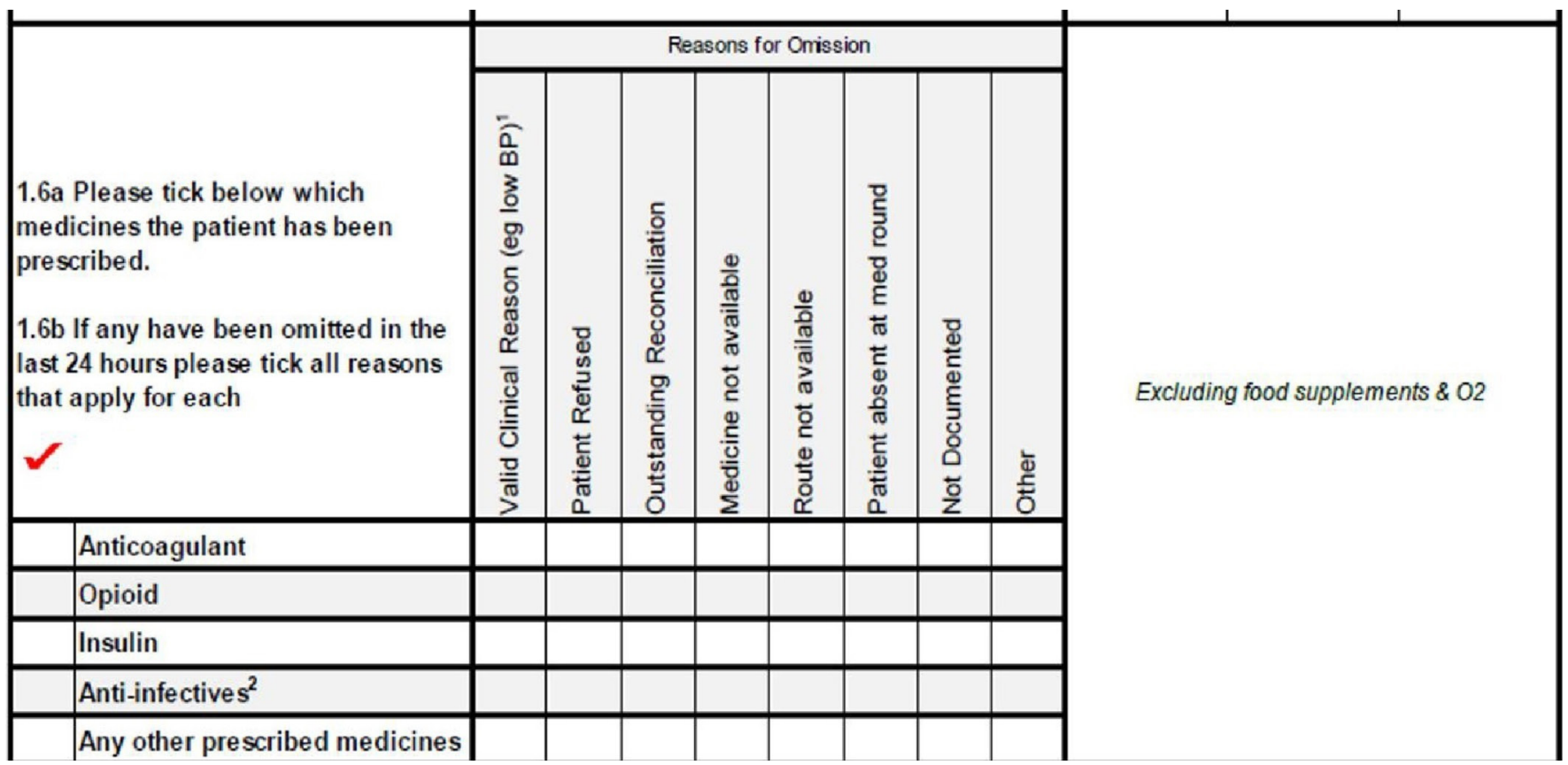

Figure 1 Medication Safety Thermometer question 1.6 (from V.16) regarding medication administration omissions. 1, According to local guidance; 2, Anti-infectives (antibiotics, antifungals, antivirals \& antimalarials).

medicines reconciliation initiation and medicine administration omissions) and triggers of actual harms (eg, low glucose levels in patients on insulin). No patient identifiable data were collected. The design and the development of the MedsST, including how questions about omissions were developed, have been reported in a previous study ${ }^{24}$ Briefly, the MedsST was developed by a large multidisciplinary steering group over a period of 9 months. The tool was officially launched in October 2013 and continued to be improved until May 2016 using ongoing feedback from both staff overseeing the use of the MedsST and frontline MedsST data collectors. The feedback led to various improvements over 16 versions of the tool, including changes in definitions and how data were collected ${ }^{24}$ MedsST data collectors included a range of healthcare staff, such as pharmacists, nurses and pharmacy technicians. Information was sourced from examination of the patient, patient report and clinical records.

For the medication administration omissions data, data collectors reviewed medical records and spoke to other healthcare professionals or patients to determine whether an omission had occurred within the last 24 hours from the time of data collection. If a patient was included as having had an omission, staff recorded the reason for the omission (eg, medicine not available).

\section{Definitions}

Figure 1 shows the precise operational definitions that were provided with the tool regarding medication administration omissions. Data were collected on all regularly prescribed medicines and not 'as required' drugs as the tool specifies that data collectors should 'Exclude PRN medicines (refers to medicines taken only when required), Stat doses (doses taken immediately and not routinely), IV (Intra-venous) fluids, $\mathrm{O}_{2}$ (Oxygen), food supplements or devices. Different doses of the same medicine count as one medicine ${ }^{\prime 25}$

\section{Study design and population}

Data collected voluntarily from 38 English NHS hospitals across England during January 2015 were examined, as the highest number of patients had been surveyed in this month. Additionally, as it was also in the early implementation of the MedsST V.16 where there was more guidance with MedsST data collection, including a national launch event that most hospitals had attended about how to use the MedsST, monthly WebExes, national guidance packages available online and a dedicated MedsST team based at Haelo to answer queries. All surveyed hospital inpatients who were prescribed one or more medications were included in this study. Patients who had not been prescribed any medicines were excluded from analysis as they were not able to have an omission. One hospital that had collected data in January 2015 was excluded as it had submitted data for one patient only.

\section{Statistical analysis}

The primary outcome measure was the point prevalence of all patients who had one or more omissions, excluding valid clinical reasons (VCRs), and the secondary outcome measure was the point prevalence of all patients who had one or more omissions, excluding both VCRs and patient refusals (PRs). An example of a VCR provided on the MedsST tool (see figure 1) would be if a patient had an omitted dose of antihypertensive medicine due to low blood pressure. Variations between demographic subgroups were examined formally using a two-step approach. $\chi^{2}$ tests and univariable logistic regression were 
applied to assess homogeneity of the prevalence of omissions between patient subgroups, and a multilevel logistic regression was performed to assess the impact of adjusting for hospitals and wards. Significance was assessed at an $\alpha$ level of 0.05 (two sided). Analyses were conducted using IBM SPSS Statistics V.23 and Microsoft Excel 2016.

In the second analytical phase, multilevel binary logistic regression was performed to ascertain the effects of patient characteristics on the odds that patients had one or more omissions. The following patient variables, available from MedsST data, were included: age group, number of medications prescribed, ward specialty and medicines reconciliation initiation status at the time of data collection. Multilevel modelling allowed us to account for the hierarchical nature of the data (hospital-ward-patient) in estimating our results. This included using fixed effects for each of the variables (predictors) of interest and random effects to account for hospital and ward-level clustering. Separate regressions were performed for omissions excluding VCRs and omissions excluding both VCRs and PRs. The latter regression, excluding PR omissions, was conducted as a sensitivity analysis.

\section{Research governance and ethics}

This study is a secondary analysis of publicly available anonymous data, as the MedsST tool does not collect any identifiable patient information. No ethical approval was required as identified using the NHS research ethics decision tool ${ }^{30}$ and the university's ethics decision tool. ${ }^{31}$ Nonetheless, high ethical standards were adhered to and, although publicly available, the names of the hospitals who collected MedsST data in January 2015 have not been published in this study.

\section{RESULTS}

A total of 7620 patients across healthcare settings were surveyed by the MedsST in January 2015. However, of these, 1717 patients were based in primary care settings and therefore excluded. Of the remaining 5903 who were hospital inpatients, 140 patients were not on any medication and 55 patients had incomplete data and were subsequently excluded. Exclusion of patients with incomplete data occurred because the number of missing values was very small ( 55 cases out of 5763 , less than $1 \%$ ). The remaining 5708 hospital inpatients included in this study were based across 320 wards in 37 hospitals.

\section{Overall omissions}

The mean rate of inpatients with medication administration omissions across all hospitals was $30 \%$ excluding VCRs ( $\mathrm{n}=1717$, 95\% CI 29 to 31). However, this varied greatly between hospitals with hospitals omissions rate ranging from $0 \%$ to $64 \%$.

\section{Drug groups omitted and reasons for omissions}

Of the patients prescribed high-risk medicines, patients prescribed insulin $(n=270)$ had the highest proportion of omissions ( $\mathrm{n}=40,15 \%, 95 \%$ CI 11 to 19$)$. Of the patients who had omissions of all medicines $(n=2256)$, the most common reason for omissions was PRs, which were reported for over half of all patients with omissions $(\mathrm{n}=1150,51 \%, 95 \%$ CI 49 to 53$)$.

Table 1 shows how different high-risk drug groups have different causes of omissions. For example, PRs were the main cause of omissions for patients prescribed insulin $(\mathrm{n}=8,20 \%, 95 \%$ CI 7 to 33$)$, opioids $(\mathrm{n}=46,54 \%, 95 \%$ CI 43 to 65$)$ and anticoagulants ( $\mathrm{n}=48,24 \%, 95 \%$ CI 18 to 30 ), but not for anti-infectives. Within the group of patients who had omissions of anti-infectives $(n=149)$, over a quarter did so due to the unavailability of their prescribed anti-infective medications $(\mathrm{n}=42,28 \%, 95 \% \mathrm{CI}$ 20 to 35). Unavailability of medicines was rarely an omission reason for patients on other high-risk medicines; for example, of patients who had had omissions of anticoagulants $(\mathrm{n}=200)$, only $2 \%$ had omissions due to anticoagulant unavailability ( $\mathrm{n}=4,95 \%$ CI 0 to 4 ).

Tables 2 and 3 show how the omission reasons varied for patients on surgical and medical wards who were prescribed high-risk drugs. For example, patients on surgical wards had omissions due to 'outstanding reconciliation' (which refers to a lack of medicines reconciliation initiation at the time of the drug being administered), although very rarely, but these were not reported at all for patients on medical wards.

The results of the multivariable modelling have been presented below in two sections; the first section reports the results of the primary analysis that included PRs, and the second section reports the results of the sensitivity analysis that excluded PRs.

\section{Multivariable model for predicating patients with medication omissions}

The multivariable logistic regression model, which was adjusted for variables at patient, ward and hospital levels, revealed that patients' age group and their medicines reconciliation initiation status were not associated with omissions (table 4). Conversely, the following characteristics were found to be significantly associated with the likelihood of a patient having one or more omissions: gender (women had a slightly higher risk of omissions), the number of medications prescribed and the specialty of the ward they were on.

As expected, an increase in the number of medicines a patient was prescribed was significantly associated with an increase in omissions; patients prescribed 20 or more medicines were around five times more likely to have omissions than patients prescribed one to four medicines (OR 4.99, 95\% CI 3.22 to $7.73, \mathrm{p}<0.001$ ). Patients on 15-19 medicines also had a threefold higher likelihood of having an omission compared with those on one to four medicines (OR 3.61, 95\% CI 2.86 to 4.56, $\mathrm{p}<0.001$ ). Additionally, patients on five to nine medicines were twice as likely to have omissions compared with those on one to four medicines (OR 2.02, 95\% CI 1.61 to 2.53, p<0.001). 


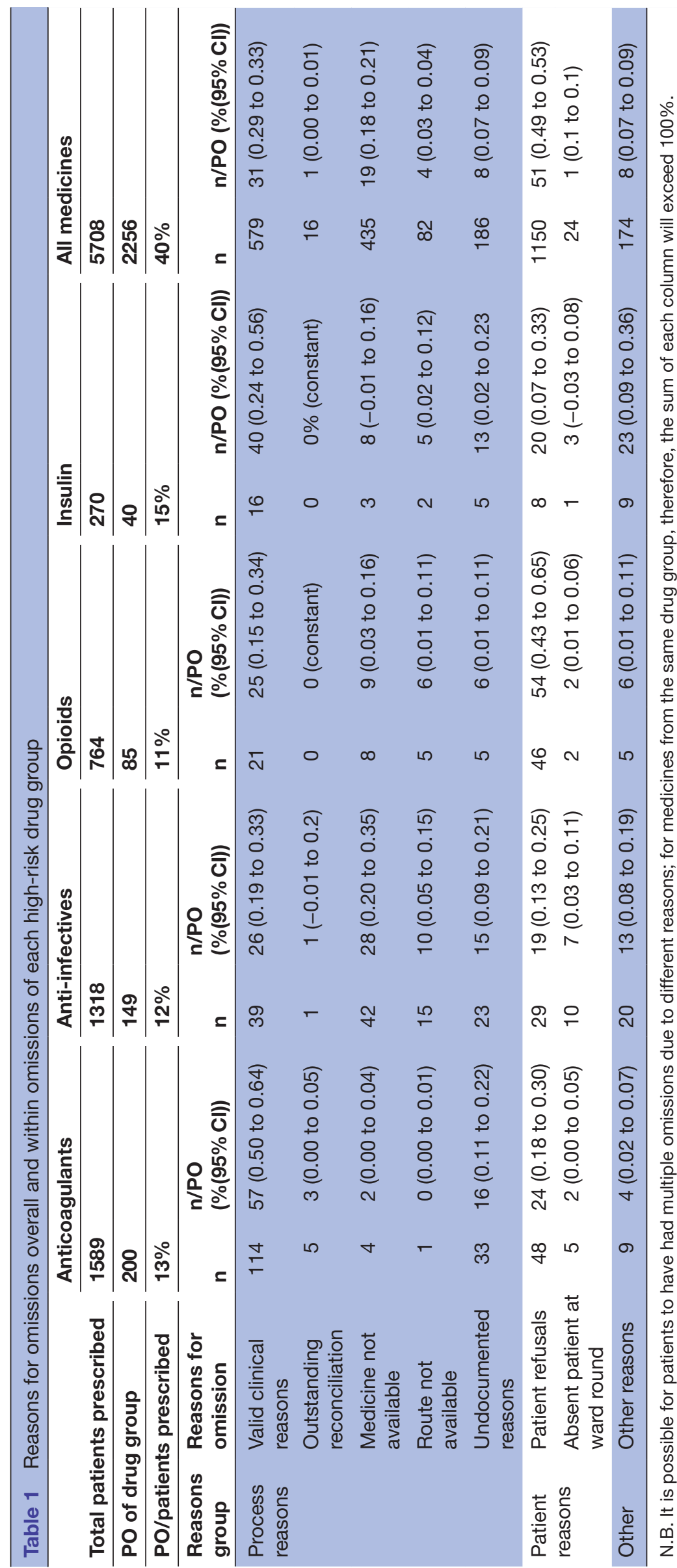




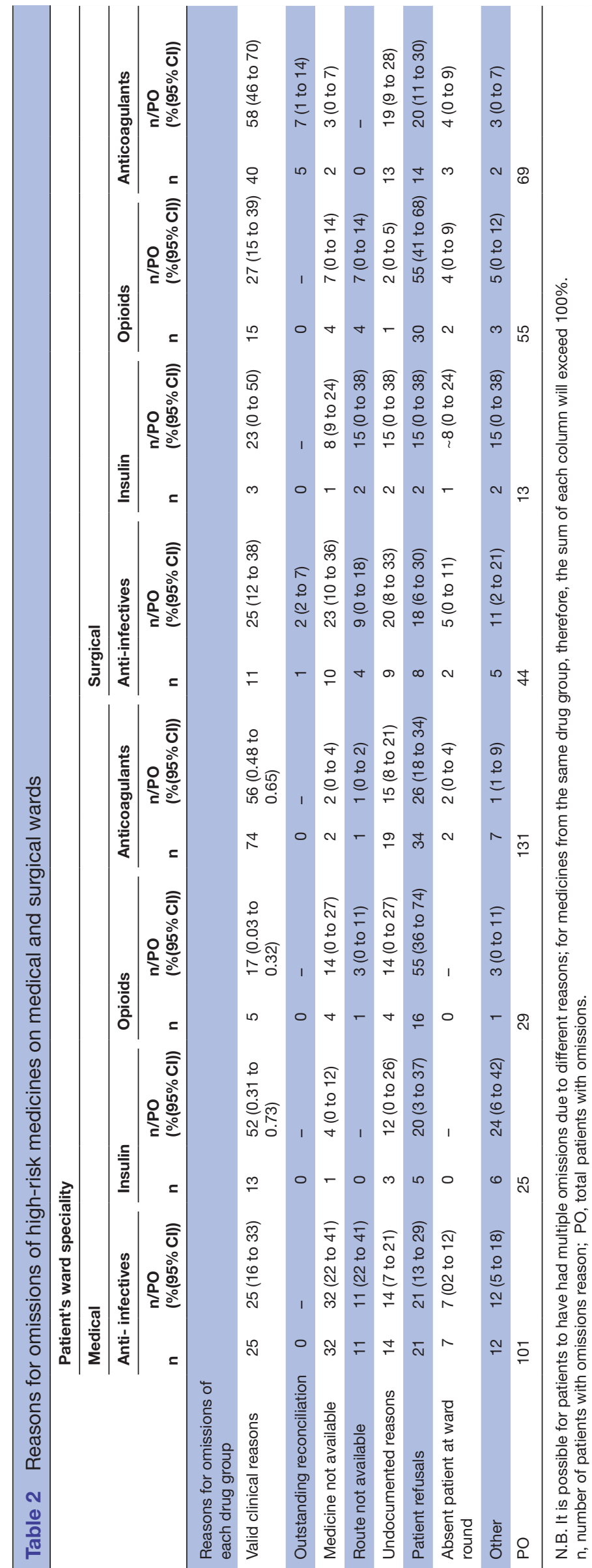

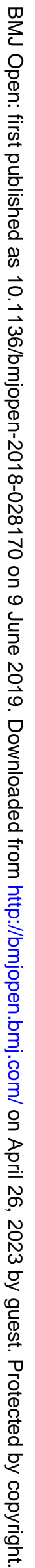




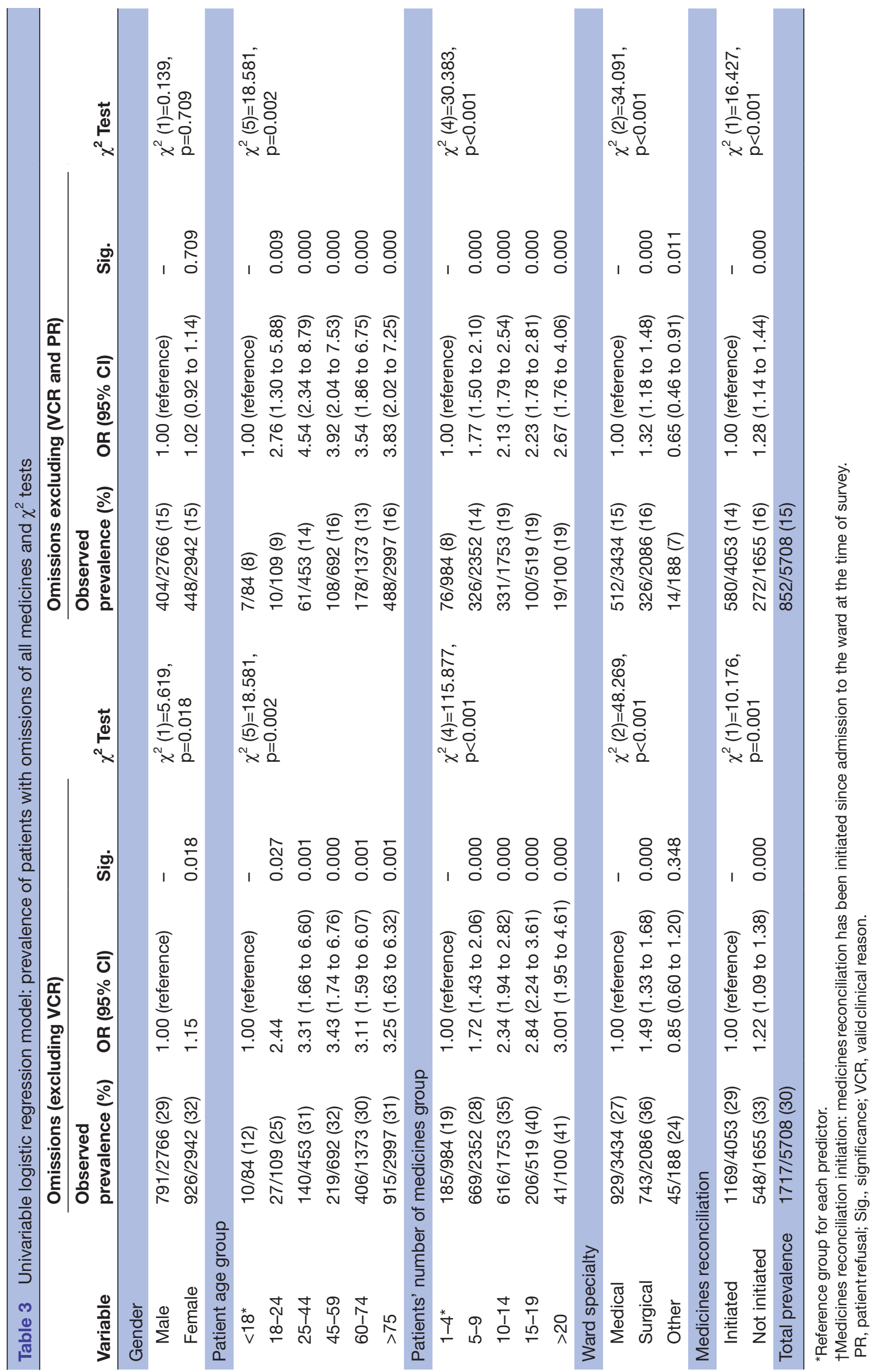




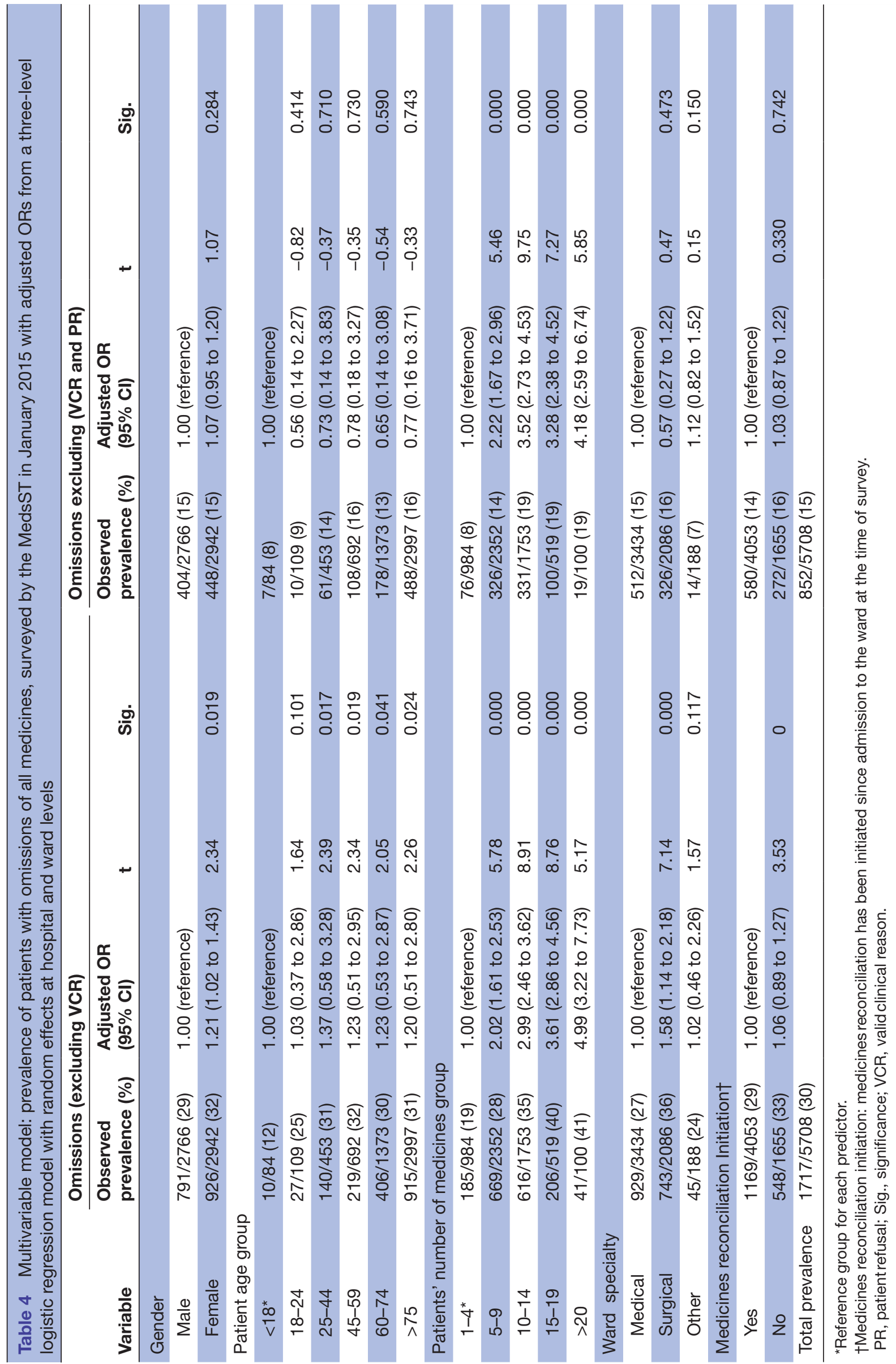


Patients on surgical wards were approximately 1.6 times more likely to have omissions than those on medical wards (OR $1.58,95 \%$ CI 1.14 to 2.18, $\mathrm{p}<0.001$ ). 'Other' wards were also included in the analysis; these included mental health, critical care, emergency department, paediatrics and obstetrics wards grouped together due to the relatively low numbers of these compared with medical and surgical wards. No significant differences were found in the likelihood of patients having omissions on medical wards compared with other wards, possibly because less data were collected on other wards or due to the mixed nature of this group.

\section{Multivariable model for predicating patients with medication omissions (excluding PRs)}

The tests were repeated excluding PRs as a sensitivity analysis, which halved the proportions of omissions ( $\mathrm{n}=852,15 \%, 95 \%$ CI 14 to 16$)$. However, excluding PRs did not alter the significance of the number of medicines prescribed as predictors; patients on more than 20 medicines were over four times more likely to have an omission than those prescribed one to four medicines (OR 4.18, $95 \%$ CI 2.59 to $6.74, \mathrm{p}<0.001)$. However, the differences between medical and surgical wards and gender became insignificant (OR $0.57,95 \%$ CI 0.27 to $1.22, \mathrm{p}=0.473$ and OR $1.07,95 \%$ CI 0.95 to $1.20, \mathrm{p}<0.284$, respectively), suggesting that PRs may drive the differences between omissions on medical and surgical wards. Table 2 shows that on both wards, $55 \%$ of patients who were prescribed opioids had refused them (medical wards: $n=16 / 29$, $95 \%$ CI 36 to 74 , and surgical wards: $n=30 / 55,95 \%$ CI 41 to 68$)$. The proportion of patients who were prescribed and refused anti-infectives, insulin and anticoagulants were all higher on medical wards, suggesting that other drugs (not classified as high risk) were driving the higher rate of all PRs on surgical wards compared with medical wards.

\section{DISCUSSION}

This study found that medication administration omissions in the hospital remain a substantial problem and are more prevalent in certain patient subgroups. The results indicated that $30 \%$ of patients had medication omissions (excluding VCRs) and that half of these were due to PRs, which were more likely for patients on surgical wards. The most strongly associated predictor of omissions in this study was found to be the number of medicines a patient was prescribed, with patients on 20 or more medicines five times more likely to have an omission then a patient on one to four medicines.

It is difficult to compare our findings to previous research about omissions rates as many studies have looked at 'doses' rather than 'patients'. However, the studies that have included data about the rates of hospital inpatients with at least one omission have reported rates between $17 \%$ and $80 \%,{ }^{12} 1420$ and our result for patients having omissions $(40 \%)$ is close to the median of this range. Furthermore, a recent study conducted specifically within an English NHS hospital reported a rate of $12.4 \%{ }^{15}$ of patients with omissions, excluding PRs and VCRs (before any interventions to improve omissions) and our result is similar to this rate $(15 \%)$.

The main reasons for omissions found in this study were PRs, followed by VCRs and then medicines not being available. Another study looking specifically at medical and surgical wards across four hospital sites also found these to be the leading causes of omissions. ${ }^{14}$ Omissions due to PRs can be grouped with omissions due to 'patients absent from ward round' to form a subgroup of reasons due to 'patient reasons'. This study highlighted that patient reasons accounted for more omissions than 'process reasons', such as 'medicine not available'.

It is important that omissions due to PRs are investigated further at local levels. While most PRs may be appropriate (eg, a patient refusing laxatives due to symptoms of diarrhoea), some PRs may not be appropriate. A previous MedsST study found that in one hospital, patients on a hepatology ward were refusing lactulose as they thought it was prescribed to treat constipation, when it was in fact used to reverse hepatic encephalopathy. ${ }^{13}$ This was addressed by extra education sessions for staff to help them manage these sort of PRs that correlated with clear improvements in omissions rates on the ward. ${ }^{13}$ Involving patients with their medication use and decisions can improve PRs, and strategies to improve medication adherence, including educating patients and healthcare professionals about medicines and the importance of taking them, should be encouraged. ${ }^{32}$

Although many previous studies evaluate proportions of dose omissions rather than proportions of patients with omissions, they have also highlighted that PRs are one of the largest reasons for omissions, reporting that $41 \%-46 \%$ of dose omissions being reported are due to PRs. ${ }^{14923}$ On the other hand, some studies have reported different reasons as the most prevalent explanation for omissions. For example, Green et al found that the most prevalent reasons for dose omissions were that the medicines were not available or that the patient was 'nil by mouth'. ${ }^{12}$ The latter definition should come under 'route not available' according to the original MedsST guidance $^{33}$; however, it is possible that it is being recorded as PR or VCR. This may explain the high rate of insulin PR and VCR omissions, considering that diabetic inpatients may be receiving variable rate insulin infusions rather than their usual insulin injections while in the hospital. ${ }^{34}$ The variations in definitions between hospitals highlight the need for standardised definitions and methodology if hospitals are to collect data to be aggregated nationally.

There are also other variations between hospitals that could have an impact on omission rates, for example, staffing levels, while we did not have access to staffing levels between the various hospitals and wards, this is another area that could be further explored. Hospitals can compare their omissions rates between wards and compare them to data on staffing levels. There are many 
other factors that can impact omission rates, and previous research has highlighted that multiple interacting error and violation-provoking conditions and latent 'system' failures can cause medication administration omissions, ${ }^{35}$ which emphasises the complexity of improving omission rates. ${ }^{36}$

Despite the complexities, there have been various efforts made to improve omissions, ${ }^{15163738}$ and while results have been promising, it has been found to be a complicated and large task. Different actions are required for individual patient subgroups. For example, while over a quarter of patients who had omissions of anti-infectives medicines did so due to the unavailability of their prescribed anti-infectives, only $2 \%$ of patients prescribed anticoagulants had omissions due to unavailability of their prescribed anticoagulants. Therefore, efforts to reduce unavailability of medicines for patient groups prescribed anti-infectives will have a larger impact than efforts to reduce omissions due to unavailability of medicines for patients prescribed anticoagulants. These issues require specific actions to help tackle a larger proportion of omissions with less resources. For example, to reduce the number of omissions of anti-infectives, senior members of the organisation must examine associated supply and administration systems to see where they can be further improved to optimise patient care. Any such improvement strategies implemented by one hospital may be easier to understand, replicate and monitor across wards and hospitals due to the use of the standardised MedsST data collection methodology, as progress can be more easily compared.

Some hospitals such as NHS University College London hospitals have already used MedsST omission data, alongside other omission audit data, for further improvement initiatives. ${ }^{38}$ At this hospital, omission data have been fed back to frontline staff by the medication safety officer alongside suggested omission improvement strategies through guidance on behalf of their medication safety committee. ${ }^{38}$ Our previous study also identified evidence of ward-level omissions improvements that had been aided by using MedsST data. ${ }^{13}$ This highlights that some use of MedsST omission data, for monitoring and aiding improvement, is occurring at ward and hospital levels, and further research is required to explore how the data are being used, and by whom.

This study has also confirmed that patients with polypharmacy are one of the main priority areas for medication safety improvement. Polypharmacy is a growing global problem due to an ageing population and increasing prevalence of multimorbidity. ${ }^{39}$ Therefore, focus is required on methods of identifying and improving unnecessary polypharmacy. For example, regular data about patients and their medicines from tools like the MedsST can be used to identify patients on greater than 10 regular medicines. ${ }^{40}$ These patient's polypharmacy can then be reviewed to identify if there is any unnecessary medicines.

Previous studies have found that omissions are more common in surgical wards than in medical wards, ${ }^{20}$ and the results of the present study suggest that PRs drive these differences. One could assume that omissions of opioids would be higher in surgical wards, as they are commonly prescribed after surgery for pain relief. However, table 2 showed that an equal proportion of patients had omissions of opioids in medical and surgical wards $(55 \%)$. Regardless of wards, a high number of patients refuse opioid medicines, which has also been found in previous research that demonstrated analgesia and anti-inflammatory medicines, such as opioids, to be associated with high rates of omissions, often due to PRs. ${ }^{14}$ Healthcare staff may need to ensure a regular review of medication so that it can be stepped down from regular to as required or discontinued if, and when, appropriate.

The results of this study indicated that medicines reconciliation initiation did not impact the likelihood of a patient having an omission. It could be argued that medicines reconciliation is more likely to cause issues with medicines not being prescribed when patients transition from other care settings into hospitals, ${ }^{41}$ rather than not administered while in hospital. However, the data about medicines reconciliation initiation could be a proxy measure for the patient's drug chart having been seen by a pharmacist and any unavailable medication ordered. This would potentially reduce omissions of medicines, particularly if bundled with interventions aimed at improving patients' transitions between care settings. ${ }^{42}$ Furthermore, medicines reconciliation could provide a potential opportunity for pharmacy staff to discuss medicines with patients and why they are refusing medications, for example, reviewing whether surgical ward patients should have their regular prescribed opioids discontinued or stepped down. Previous research has highlighted that many of the benefits of resolving unintended discrepancies during the medicines reconciliation process may not become apparent for months after discharge. ${ }^{42}$

The current WHO global patient safety challenge, 'Medication without harm', has identified three early priority action areas: high-risk situations, polypharmacy and transitions of care. ${ }^{43}$ Although we focused on omissions, a very specific area of medication safety, our findings support the need for improvement of these areas. Patients with polypharmacy were significantly more likely to have omissions, patients on particular high-risk medicines are at higher risk of missing medicines and, in terms of improving transitions of care, patients who do not have medicines reconciliation started within 24 hours were more likely to have omissions. Improvement of omissions in all of these areas is required.

\section{Strengths and limitations}

This study adds to knowledge about patients with omissions and potential predictors of patients having omissions using a large data set, from a variety of wards with different specialties across 37 hospitals. The data used in this study have also been collected using a universally available tool and standardised methodology. As this study focuses on the proportion of patients with omissions, 
rather than on the number of missed medicines, it could aid healthcare professionals to identify or confirm which patient groups are at higher risk of omissions and adapt omissions improvement strategies accordingly.

This study and data collected by the MedsST were not without limitations. Although the data collection method was standardised, multiple healthcare staff were involved, leading to potential variations in data collection practice, even with the guidance provided. For example, although the MedsST guidance states that only data regarding regular medicines (rather than as required medicines) should be collected, it is not clear whether this guidance has been adhered to. Some of the differences in data collection were somewhat addressed by the testing of phases of the MedsST as a variety of healthcare professionals contributed to the selection of questions, furthermore a dedicated safety thermometer team based at Haelo, Salford, supported MedsST data collectors and helped to rectify data collection issues as they arose. ${ }^{24}$

During MedsST data collection, no information about data collectors is obtained; therefore, this could not have been included in the regression model. It would be useful, for analysis purposes. if future versions of the tool included a question about the job role of the data collector. Further work about inter-rater reliability is recommended as previous research has highlighted that there can be differences in how different healthcare professionals report medication errors; however, these studies have looked at medication error reporting scales rather than routinely collected medication safety data.

Other limitations associated with the data collection were that drug charts formats between hospitals differ and that collection of data relied on complete medical records and drug charts. If these patient documents were incomplete, or the data collected failed to identify or to record omissions, this would result in our data underestimating the actual omission rate. However, the median number of patients that data were collected on per ward was calculated to be 19 (IQR 12-24) and 129 patients per hospital (IQR 47-207). As these ranges were not wide, the finding suggests that the data are being collected somewhat consistently across hospitals and wards. Furthermore, NHS staff trust the MedsST data collected in hospitals ${ }^{27}$ and have used MedsST omissions data to conduct and monitor further improvement work successfully. ${ }^{13}$

Another issue that should be considered when using MedsST data is that if prescribing errors are recorded in the patients' drug charts, they may lead to administration omissions errors ${ }^{36}$ or recording of inaccurate medication administration omissions data. Previous research has highlighted that ${ }^{35} 44$ other failures in the medicines use process, such as prescribing errors, can contribute to medication administration omissions, as well as other medication administration errors. ${ }^{35}$ For example, if a medication reconciliation had not been performed and a medication was prescribed by mistake, if the patients had not taken this at home they might refuse to take it in the hospital, with the omission classified as a PR or VCR. It is important for organisations to review their omissions data and to investigate it at local levels so that they can identify and improve issues with medication use and data collection processes.

While the MedsST data focuses on four high-risk drug groups, there may be trends in omissions of other drug groups that can be improved, and it is important that omissions data are reviewed at local levels to investigate this as done by some ward staff that collect MedsST data. ${ }^{13}$

While this was a large study that used multilevel regression modelling to account for variance between the wards and hospitals, its findings may not be generalisable to other hospitals, particularly those in other countries. Furthermore, all hospitals included collected data voluntarily in January 2015, which may mean they are more proactive about improving patient safety, further underestimating the prevalence across England.

\section{CONCLUSION}

This study found that a large proportion of patients are affected by medication administration omissions; however, many of these are due to VCRs, or possibly appropriate PRs. Overall, the main predictor for a patient having medication omissions is the number of medicines that they have been prescribed.

\section{Author affiliations}

${ }^{1}$ Division of Pharmacy and Optometry, School of Health Sciences, The University of Manchester, Manchester Academic Health Science Centre, Manchester, UK

${ }^{2}$ Centre for Biostatistics, University of Manchester, Manchester Academic Health

Science Centre, Manchester, UK

${ }^{3}$ Research and Innovation, Salford Royal NHS Foundation Trust, Salford, UK

${ }^{4}$ Haelo, Salford Royal Foundation Trust, Salford, UK

${ }^{5}$ Institute for Healthcare Improvement, Cambridge, Massachusetts, USA

${ }^{6}$ Harvard Medical School, Boston, Massachusetts, USA

${ }^{7}$ Greater Manchester Patient Safety Translational Research Centre, National Institute for Health Research (NIHR), Greater Manchester, UK

Acknowledgements The authors thank all healthcare staff who have collected Medication Safety Thermometer (MedsST) data and the expert group who led the development of the MedsST. The authors also thank Haelo for providing access to the raw data.

Contributors All authors have made substantial contributions to the conception or design of the work, and have been involved in acquiring, analysing or interpreting the data. All authors have been active in drafting, critically reviewing and revising the manuscript and have approved the final version to be published. Concept: PR, DMA, MPT, GP and AH. Data analysis: PR, CH, DMA, MPT and GP. Article drafting: PR, MPT and DMA. Critical revision: all authors.

Funding This work was funded by Haelo, an independent innovation and evaluation organisation hosted by Salford Royal Foundation Trust.

Competing interests The first author of this article, PR, has the following competing interests: he is a PhD student funded by Haelo who facilitated the initial development of the tool being evaluated in the study. However, PR is based at the University of Manchester and Haelo had no role in the study design.

Patient consent for publication Not required.

Provenance and peer review Not commissioned; externally peer reviewed.

Data sharing statement The Medication Safety Thermometer (MedsST) data for all organisations collecting data, which have been referred to in this study, are available via its website (https://www.safetythermometer.nhs.uk). To access the dedicated dashboard presenting the data in graphical format, the 'Medication' 
tab must be selected, followed by the 'analyse data' button. Since this study was conducted, management of the MedsST data has been transferred from Haelo to the Quality Observatory team at South, Central and West Commissioning Support Unit on behalf of NHS Improvement, which should be contacted regarding extra data.

Open access This is an open access article distributed in accordance with the Creative Commons Attribution Non Commercial (CC BY-NC 4.0) license, which permits others to distribute, remix, adapt, build upon this work non-commercially, and license their derivative works on different terms, provided the original work is properly cited, appropriate credit is given, any changes made indicated, and the use is non-commercial. See: http://creativecommons.org/licenses/by-nc/4.0/.

\section{REFERENCES}

1. Kohn LT, Corrigan JM, Donaldson MS. To err is human: building a safer health system. Washington, D.C. US: National Academies Press, 2000.

2. de Vries EN, Ramrattan MA, Smorenburg SM, et al. The incidence and nature of in-hospital adverse events: a systematic review. Qual Saf Health Care 2008;17:216-23.

3. Leape LL. Errors in medicine. Clin Chim Acta 2009;404:2-5.

4. Keers RN, Williams SD, Cooke J, et al. Prevalence and nature of medication administration errors in health care settings: a systematic review of direct observational evidence. Ann Pharmacother 2013;47:237-56.

5. Cottney A. Using league tables to reduce missed dose medication errors on mental healthcare of older people wards. BMJ Qual Improv Rep 2015;4:u204237.w3567.

6. Elliott RA, Camacho E, Campbell F, et al. Prevalence and Economic Burden of Medication Errors in The NHS in England. Rapid evidence synthesis and economic analysis of the prevalence and burden of medication error in the UK. 2018.

7. Bates DW, Boyle DL, Vander Vliet MB, et al. Relationship between medication errors and adverse drug events. J Gen Intern Med 1995;10:199-205.

8. Kopp BJ, Erstad BL, Allen ME, et al. Medication errors and adverse drug events in an intensive care unit: direct observation approach for detection. Crit Care Med 2006;34:415-25.

9. Cousins D, Dewsbury C, Matthew L, et al. Safety in doses: medication safety incidents in the NHS: The National Patient Safety Agency, 2007.

10. Ghaleb MA, Barber N, Franklin BD, et al. The incidence and nature of prescribing and medication administration errors in paediatric inpatients. Arch Dis Child 2010;95:113-8.

11. Taxis K. Administration of medication. In: Tully MP, Franklin BD, eds. Safety in Medication Use. UK: CRC Press, 2016:35-44.

12. Green CJ, Du-Pre P, Elahi N, et al. Omission after admission: failure in prescribed medications being given to inpatients. Clin Med 2009;9:515-8.

13. Rostami P, Harrison A, Parry G, et al. A qualitative study exploring how routinely collected Medication Safety Thermometer data have been used for quality improvement purposes using case studies from three UK hospitals. BMJ Open 2019;9:bmjopen-2018-025292.

14. Warne $\mathrm{S}$, Endacott $\mathrm{R}$, Ryan $\mathrm{H}$, et al. Non-therapeutic omission of medications in acutely ill patients. Nurs Crit Care 2010;15:112-7.

15. Baqir W, Jones K, Horsley W, et al. Reducing unacceptable missed doses: pharmacy assistant-supported medicine administration. Int $J$ Pharm Pract 2015;23:327-32.

16. Li XJ, Moola S. Strategies to reduce medication omissions in an acute medical unit of an acute tertiary hospital: a best practice implementation project. JBI Database System Rev Implement Rep 2016;14:347-61.

17. Johnson M, Sanchez P, Zheng C, et al. Feasibility study of interventions to reduce medication omissions without documentation: recall and check study. J Nurs Care Qual 2017;32:E8-16.

18. Dalton BR, Sabuda DM, Bresee LC, et al. Use of an electronic medication administration record (eMAR) for surveillance of medication omissions: results of a one year study of antimicrobials in the inpatient setting. PLoS One 2015;10:e0122422.

19. Coleman JJ, McDowell SE, Ferner RE. Dose omissions in hospitalized patients in a UK hospital: an analysis of the relative contribution of adverse drug reactions. Drug Saf 2012;35:677-83.

20. Leite B, Mistro S, Carvalho C, et al. Cohort study for evaluation of dose omission without justification in a teaching general hospital in Bahia, Brazil. Int J Qual Health Care 2016;28:288-93.
21. Cottney A, Innes J. Medication-administration errors in an urban mental health hospital: a direct observation study. Int $J$ Ment Health Nurs 2015;24:65-74.

22. Hunt KV, Harding AM, Taylor SE, et al. Evaluation of medication dose omissions amongst inpatients in a hospital using an electronic Medication Management System. J Eval Clin Pract 2018;24:688-94.

23. Lundy E, McMullan D, McShane P, et al. Polypharmacy and drug omissions across hospices in Northern Ireland. J Palliat Med 2013;16:1446-9.

24. Rostami P, Power M, Harrison A, et al. Learning from the design, development and implementation of the Medication Safety Thermometer. Int J Qual Health Care 2017;29:301-9.

25. NHS Improvement. The NHS Safety Thermometers: NHS Improvement. www.safetythermometer.nhs.uk (accessed $06 \mathrm{Ju}$ 2018).

26. Cousins DH, Gerrett D, Warner B. A review of medication incidents reported to the National Reporting and Learning System in England and Wales over 6 years (2005-2010). Br J Clin Pharmacol 2012;74:597-604.

27. Rostami P, Ashcroft DM, Tully MP. A formative evaluation of the implementation of a medication safety data collection tool in English healthcare settings: A qualitative interview study using normalisation process theory. PLoS One 2018;13:e0192224.

28. Benchimol El, Smeeth L, Guttmann A, et al. The REporting of studies Conducted using Observational Routinely-collected health Data (RECORD) statement. PLoS Med 2015;12:e1001885.

29. von Elm E, Altman DG, Egger M, et al. STROBE Initiative. The Strengthening the Reporting of Observational Studies in Epidemiology (STROBE) statement: guidelines for reporting observational studies. PLoS Med 2007;4:e296.

30. NHS Health Research Authority, Medical Research Council. Do I need NHS REC approval. http://hra-decisiontools.org.uk/ethics/ (accessed 23 Nov 2018).

31. The University of Manchester. Does your research require ethics approval? http://www.staffnet.manchester.ac.uk/services/rbess/ governance/ethics/does-your-research-require-ethical-approval/ (accessed 03 Apr 2018).

32. Atreja A, Bellam N, Levy SR. Strategies to enhance patient adherence: making it simple. MedGenMed 2005;7:4

33. Cousins DW, Jani S, Power Y, et al. Medications Safety Thermometer - A preliminary pilot quide. London, UK: NHS, 2014

34. Collard B, Sturgeon J, Patel N, et al. The Variable Rate Intravenous Insulin Infusion Protocol. BMJ Qual Improv Rep 2014;2:u203060. w1409.

35. Keers RN, Plácido M, Bennett K, et al. What causes medication administration errors in a mental health hospital? A qualitative study with nursing staff. PLoS One 2018;13:e0206233.

36. Keers RN, Williams SD, Cooke J, et al. Causes of medication administration errors in hospitals: a systematic review of quantitative and qualitative evidence. Drug Saf 2013;36:1045-67.

37. Keers RN SE, Kontopantelis E, et al. The Evaluation of pharmacy TECHnician supported MEDication administration rounds (TECHMED) on reducing omitted doses: a pilot randomised controlled trial and process evaluation in a university teaching hospital. 2017.

38. Jani Y, Philpott S. Reducing avoidable dose omissions: A quality improvement initiative using time series analysis to assess the impact of a complex intervention University College London Hospitals: NHS. 2014 https://www.sps.nhs.uk/wp-content/uploads/2016/08/NNUCLH Dose-Omissions 2014 IFQSHC.pdf (accessed 26 Feb 2019).

39. Duerden M, Avery T, Payne R. Polypharmacy and medicines optimisation: making it safe and sound: King's Fund, 2013.

40. Phippen A, Pickard J, Steinke D, et al. Identifying, highlighting and reducing polypharmacy in a UK hospice inpatient unit using improvement Science methods. BMJ Qual Improv Rep 2017;6:u211783.w5035.

41. van den Bemt PM, van der Schrieck-de Loos EM, van der Linden C, et al. Effect of medication reconciliation on unintentional medication discrepancies in acute hospital admissions of elderly adults: a multicenter study. J Am Geriatr Soc 2013;61:1262-8.

42. Kwan JL, Lo L, Sampson M, et al. Medication reconciliation during transitions of care as a patient safety strategy: a systematic review. Ann Intern Med 2013;158(5 Pt 2):397-403.

43. World Health Organization (WHO). Medication Without Harm - Global Patient Safety Challenge on Medication Safety. Geneva, Switzerland: World Health Organization (WHO), 2017.

44. Tully MP, Ashcroft DM, Dornan T, et al. The causes of and factors associated with prescribing errors in hospital inpatients: a systematic review. Drug Saf 2009;32:819-36. 